\title{
Adoption of RFID technologies in UK logistics: Moderating roles of size, barcode experience and government support
}

\begin{abstract}
Due to globalization, logistics has become an important part in the supply chain. Many logistics service providers have realised the importance of adoption of technologies that can help manufacturers, warehouses, and retailers to communicate with each other more efficiently. Among many logistics technologies, Radio frequency identification (RFID) has been identified as an important technology to improve logistics operations and supply chain management, and thus is increasingly gaining both practitioners' and researchers' attention. The purpose of this study is to identify the impact of usability features of RFID in the adoption of the technology by the logistics sector in the UK. We have used questionnaire survey method to collect data from the UK Logistics firms. The analysis of the data shows that the usability of RFID technology positively influences adoption of technology. We have further tested the moderating effects of firm size, experience with barcode use, and government support in adopting RFID. Our results show that government support strongly moderates the link between usability of RFID and its adoption but size and experience with barcode do not moderate this link. We elaborate the contributions of the study and managerial implications of our results in this paper.
\end{abstract}

Key Words: RFID, technology acceptance model, barcodes, government support 


\section{Introduction}

Due to globalization, logistics has become a strategic factor in creating competitive advantage in supply chains. With help of efficient and effective logistics, it is possible to ensure smooth flow of raw materials, products and related information from the primitive occurring points to the final consumption points (Bowersox and Closs, 1996). Since the contribution of logistics in the overall competitiveness of companies has been recognised by companies, many of them have realised the need to adopt technological innovations (Lin and Ho, 2009a). Several technologies are available for improving the efficiency and effectiveness of integrated global logistics. They are related to expert systems and artificial intelligence, and include technologies such as Enterprise Resource Planning and Radio Frequency Identification (RFID).

Radio frequency identification (RFID) is one such recent innovation in the logistics industry, and is the focus of the research reported in this paper. RFID is a type of famous autoidentification technology that uses radio frequency (RF) waves to identify, track and locate individual physical items. A typical RFID system consists of three components: an antenna, RFID tags, and a RF reader. This technology is widely used in many applications including manufacturing and distribution of products (Cardiel et al., 2012; Lin and Ho, 2009a), Businessto-Business (B2B) logistics, Business-to-Consumer (B2C) marketing and after-sales service (Curtin et al., 2007).

Since firms have recognised the potential of RFID in integrating their logistics activities, its adoption has been growing regularly. For example, the US retail giant Wal-Mart has been using RFID in their operations for the past few years. From January 2005, the company has also insisted its top 100 suppliers to adopt RFID (Lin et al, 2005). Many other big companies such as Federal Express, Dell, Proctor and Gamble, and the American Defence Department have also adopted RFID technology in their supply chain systems (Lin and Ho, 2009a). Due to the increasing popularity of RFID, several research studies have recently been conducted to understand the impact of the technology on performance of firms. Many research articles have focused either on the general overview of RFID or on the applications of RFID in various industries such as fashion (Luyskens and Loebbecke, 2007; Moon and Ngai, 2008), services (Lee et al., 2008), retail and manufacturing sectors (Bhattacharya et al., 2008), library (Rong, 2004), and automotive industry (Schmitt et al., 2007). However, there is a limited discussion in understanding the impact of usability of RFID on its adoption, and in understanding how this relationship gets affected by other related factors, especially in the logistics sector. In this study, we first try to understand the relationship between the usability of RFID and the adoption, and then check whether this relationship is moderated by (i) the size of the company, (ii) experience with the current technology (barcode) being prominently used by the company and (iii) the level of government support for RFID.

The rest of the paper is organised as follows: Section 2 introduces the background of RFID. This section also explains theoretical underpinning and hypothesis development. Section 3 presents research methodology with detailed data description. Section 4 explains data analysis. Section 5 discusses the results and the managerial implications. The final section summaries the conclusion with limitations and future research possibilities. 


\section{Research Background and hypotheses development}

\subsection{Background study on RFID}

RFID is one of the latest identification technology used in various applications. Based on the level of usage, ranging from 1 meter to several meters, the cost of RFID tags are also different. Attaran (2007) has described the RFID technology in simple terms. Accordingly, RFID tags are the chips that are embedded in the product, pallet, or case. They are used to store and transmit information about the specific unit. RFID readers are radio frequency transmitters and receivers, controlled by a micro-processor or digital signal processor that communicates with the tags. The middleware is an intermediate layer between the RFID readers and the enterprise application systems (Wang et al., 2010). It is used for reader and device management to provide a common interface to configure, monitor, deploy, and issue commands directly to readers (Curtin et al., 2007; Sweeney, 2005). RFID system is always connected to an enterprise application system for data processing in support of business activities (Wang et al., 2010).

Though RFID is a relatively new technology, many companies have recognised the potential of this technology for handling the complexity of globalisation and for creating a balance between cost and performance in supply chains. This has also arose interest in this technology among consultants, academics and researchers worldwide, which is indicated by the increasing volume of articles on the subject in trade publications and scholarly journals (e.g., Chen et al., 2012; Riedel et al., 2008; Lee et al., 2013; Li et al., 2010; Poon et al., 2009; Tan and Chang, 2010; Sundaram et al., 2010). Li et al. (2010) classified the literature of RFID into three areas: RFID general overview, analytical studies, and empirical studies. General overview of the literature covers the applications of RFID in supply chains, challenges and strategies of RFID (Spekman and Sweeney, 2006; Twist, 2005; McFarlane and Sheffi, 2003). Analytical studies on RFID cover financial implications and inventory issues in various sectors including manufacturing and distributions (Ozelkan and Galambose, 2008; Ustundag and Tanyas, 2009). Empirical studies includes cases of Wal-Mart (Hardgrave et al., 2008a;b), Sainsbury's (Karkkainen, 2003), Volvo (Holmqvist and Stefansson, 2006a,b), Hong Kong aircraft engineering company (Ngai et al., 2007) and many others.

A notable absence in the above literature is the focus of RFID on the logistics sector. Specifically, there is no prior research that attempted to understand the adoption of RFID technologies in the UK logistics sector from the theoretical lens of technology acceptance model (TAM). This study attempts to fill this gap.

\subsection{Theoretical background and hypothesis development}

Technology adoption in any company is normally based on two important criteria: usefulness of the technology to the organisation and the ease of use of the technology (Davis et al.,1989; Hossain and Prybutok, 2008; Muller-Seitz, et al., 2009; Pai and Huang, 2011). Recently, it has been applied to the introduction of healthcare information systems (Chong and Chan, 2012; Pai and Huang, 2011). RFID technology is being used widely in many university libraries (Hossain and Prybutok, 2008), and also in the German electronic retail sector (MullerSeitz et al., 2009). TAM, in its original form, assumes that perceived usefulness and perceived 
ease of use are main factors in persuading the adoption of a new technology (Davis et al., 1989; Yi and Hwang, 2003). Venkatesh and Davis (2000) later discussed a revised and upgraded TAM to include the intention to use as another factor. Additionally, in Hossain and Prybutok's (2008) study, the TAM was extended by adding perceived cultural influence, perceived privacy, perceived regulations' influence, and perceived security to the model.

The literature generally has confirmed a close association between usefulness/ease of use and adoption. For example, Pai and Huang's (2011) research on the use of healthcare information system pointed out that the relationship between perceived usefulness and users' intention to use is positive. Muller-Seitz et al. (2009) also found that the better the perceived usefulness of RFID in retailing, the better the customer acceptance of RFID. This is because if the RFID technology leads to reduced costs and time, improved security of cargos, accuracy of stock records, tracking of containers and efficiency, and some other benefits to the users, the perceived usefulness is likely to be high (Muller-Seitz et al., 2009). Also, people tend to use RFID if it is easy to use, less stressful or less complex to use and easy to integrate with company's existing information infrastructure (Muller-Seitz et al., 2009; Pai and Huang, 2011). In this study, we have combined the ideas of ease of use and usefulness of RFID technology as a single factor, namely usability, and posit our first research hypothesis.

H1: Usability of RFID technology will have a positive impact on its adoption.

Although many companies will try and adopt RFID if the technology makes running of the business easy, there are other external factors which may slow down or otherwise affect the adoption of this technology. We specifically focus on three important moderators here.

Our first factor is the size of the company. Smaller companies may not have sufficient resources to invest in newer technologies such as RFID, which may limit the usability of the technology and impact adoption adversely. This moderating role of the size of the company has been echoed in several previous studies in different research contexts (Anderson, 2003; Zona et al., 2012). Thus we feel that the link between usability and adoption of RFID is more effective for bigger companies compared to smaller companies. This is highlighted in the following hypothesis.

H2: Size of a company will positively moderate the relationship between usability and adoption of RFID.

Our second moderating variable is the experience of a company in using barcode technology, which is a technology closely related to RFID. The barcode technology has been used in the service sector since the mid-1970s (Attaran, 2007). It is a line-of-sight technology, which means a scanner has to 'see' the barcode to read it (Attaran, 2007). Barcodes are part of every purchase and have become the ubiquitous standard for identifying and tracking products (White et al., 2007). However some environmental conditions, such as temperature, dirt or hazardous contamination, can adversely affect the effectiveness of barcode scanning on a label. RFID technology is generally seen as an improvement of barcodes and it is believed that the experience in using barcodes will positively influence the expertise in using RFID (Wyld, 2006). Based on these observations, we develop our next hypothesis. 
H3: A company's experience in using barcodes will positively moderate the relationship between usability and adoption of RFID.

Government regulations can encourage or discourage the adoption of innovations (Lin and Ho, 2009a). Government can provide financial incentives and help training manpower with logistics skills for more effective RFID implementation. This was also echoed in preliminary interviews we carried out prior to developing a large scale study. We found that some companies adopted the RFID technology since they received some support from local governments. Thus, we have chosen our third moderating variable - government support. We hypothesise that a higher the level of government support will help in building stronger links between usability and adoption.

H4: Government support will positively moderate the relationship between usability and adoption.

\section{Figure 1: Research hypotheses}

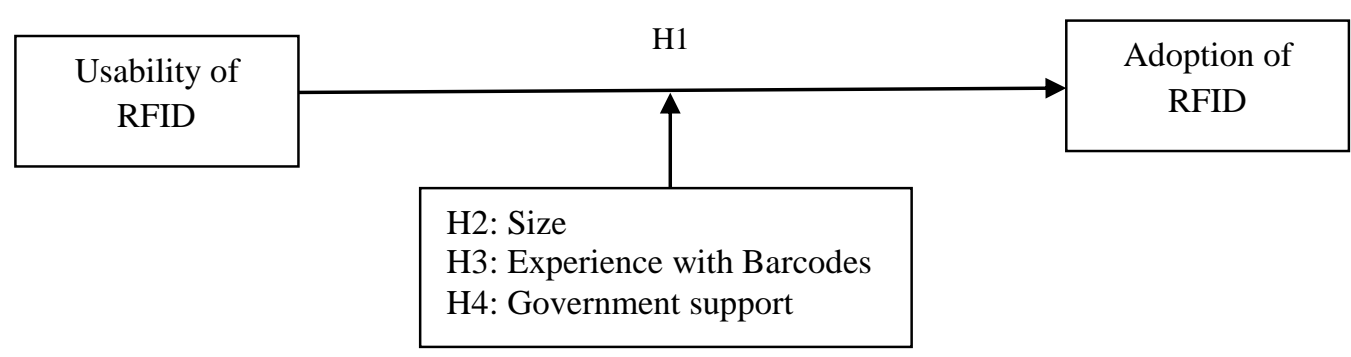

To test these research propositions $\mathrm{H} 1$ - H4, given in Figure 1, we have used a survey questionnaire to collect data and SPSS to analyse the data.

\section{Research methodology}

\subsection{Data description}

We have developed a questionnaire survey based on the literature and preliminary interviews with three local companies. Accordingly, the questionnaire was focused on main elements - usability of RFID, government support, size, barcode use and RFID adoption. A 7point Likert scale was used for all items in this study, with the responses rated as follows: 1 as strongly disagree, 2 as disagree, 3 as somewhat disagree, 4 as neither agree nor disagree, 5 as somewhat agree, 6 as agree, and 7 as strongly agree. The survey was conducted during June August 2011 and it was administered in the UK. Contact details of UK Logistics companies whose main activity was logistics and/or related areas were obtained from the Chartered Institute of Logistics and Transport (CILT) in the UK. Specifically, the areas of the chosen companies belonged to one or more of the following: logistics, freight forwarding, warehousing $\&$ distribution, couriers/parcels-main distribution, and, haulage contracting \& shipping. We focussed on these areas on the basis of recommendations from a related previous study (Riedel et al., 2008). 
CILT (UK) is a pre-eminent independent professional body for individuals associated with logistics, supply chains and all transport throughout their careers. CILT (UK) was chosen to be the major source of companies' contact information because its Knowledge Centre has the most comprehensive, accurate and up-to-date database of Logistics companies in the UK. According to their database, there are 71905 companies engaged in the UK logistics industry. Of those 71905 companies, 3533 companies were randomly selected. Cover letters with links to the online questionnaires were emailed to the owners/managers/directors of those 3533 companies. Since the response rate was too low, another 200 companies from the 71905 companies in the UK Logistics industry were randomly selected. Prior to the large scale survey, a pilot test of questionnaires was conducted with academics and selected industry participants. Questionnaires with cover letters and stamped addressed envelopes were mailed to managers/directors of those 200 companies. As an attempt to maximize the response rate, reminders were sent once per fortnight to companies via email during the survey period (i.e. June - August 2011). Consequently, a total of 174 questionnaires (consisting of 11 returned by post and 163 collected online) were received. Eliminating the incompletely filled-in questionnaires, the remaining number of valid questionnaires is a total of 107 (consisting of 4 completed questionnaires returned by post and 103 collected online).

Nearly $74 \%$ of the respondent companies were small to medium size companies with less than 250 employees. The largest number of respondents operated in the logistics (40\%) business, followed by freight forwarding (20\%), and warehousing and distribution business $(26 \%)$.

To signify the reliability of the survey responses, the current positions of respondents in their companies and the length of working experience in their current position were asked in the questionnaires. The majority of respondents were managers (50\%), followed by directors/board members (38\%) and other positions (13\%) such as company owners, sales assistants, technical assistants, operation supervisors and logistics coordinators. Over $50 \%$ of respondents had more than 6 years of working experience in their current position.

\subsection{Measure purification and descriptive data analysis}

Statistical Package for the Social Sciences (SPSS), a computer program for statistical analysis, has been used to run factor analysis, reliability analysis, correlation analysis and regression analysis in this study.

Table 1: Factor analysis and descriptive statistics 


\begin{tabular}{lccccc}
\hline & Loading & Mean & SD & \% of variance explained & $\begin{array}{c}\text { Composite } \\
\text { reliability }\end{array}$ \\
\hline Usability & & & & $\mathbf{9 7 . 1 4 5}$ & $\mathbf{0 . 9 9}$ \\
(Cronbach $\alpha=0.99)$ & .986 & 4.26 & 1.827 & & \\
Security & .982 & 4.56 & 1.839 & & \\
Cost & .987 & 4.29 & 1.846 & & \\
Accuracy of stock records & .986 & 4.25 & 1.866 & & \\
Improve tracking & .989 & 4.36 & 1.846 & & \\
Save time & .987 & 4.40 & 1.781 & & \\
Overall efficiency & .983 & 4.42 & 1.760 & & \\
Easier than convention & .986 & 4.40 & 1.797 & & \\
Ease of use & .981 & 4.17 & 1.797 & & \\
Less stress & .988 & 4.39 & 1.806 & & \\
Easy to integrate & & & & $\mathbf{7 2 . 6 2 6}$ & \\
\hline Adoption & & & & \\
(Cronbach $\alpha=0.669)$ & .895 & 3.66 & .686 & & \\
Responsibility & .799 & 3.93 & .730 & & \\
Future investment & .860 & 3.41 & 1.928 & & \\
Current stage of adoption & & & & $\mathbf{9 5 . 3 5 1}$ & \\
\hline Government support & & & & & \\
(Cronbach $\alpha=0.984)$ & & & & \\
Finance support & 0.974 & 4.12 & 1.784 & & \\
Project support & 0.976 & 3.91 & 1.680 & & \\
Training & 0.980 & 3.99 & 1.729 & & \\
Regulatory support & 0.977 & 3.90 & 1.704 & & \\
\hline & & & & & \\
\hline
\end{tabular}

Factor analysis (see Table 1) has confirmed the presence of three factors 'usability', 'adoption' and 'government support'. The factor 'usability' has 10 questionnaire items. As mentioned in Section 2, the factor 'usability' was usually included as two different factors ease of use and usefulness in several previous research studies (Davis et al., 1989; Venkatesh and Davis, 2000; Hossain and Prybutok, 2008). The factor 'adoption' has 3 items and the factor 'government support' has 4 items. We have measured the factor 'adoption' using 3 items namely - responsibility of the company in executing the actual adoption of RFID, future plans of company's investment in RFID and current stage of adoption (Riedel et al., 2008). Similarly 'government support' has been measured using four items, namely finance support, project support, training, and regulatory support (Lin and Ho, 2009b).

Factor loadings of all the items are above recommended limit of 0.4 (Hair et al., 2006). Reliabilities of these factors have been measured by Cronbach's alpha (Nunnally, 1978). All the factors have Cronbach's alpha above 0.65, which is the recommended minimum acceptable value for internal consistency of the measures (Hossain and Prybutok, 2008). In addition, to examine significant differences among the estimated parameters to the model (i.e., construct validity), we have tested the variance extracted which is within the acceptable range of more than 0.50 (Fornell and Larcker, 1981)). To verify that the data set is suitable for factor analysis, the Kaiser-Meyer-Olkin Measure of Sampling Adequacy (KMO) value has been measured. KMO value of 0.50 or above with significant Bartlett's Test of Sphericity value (i.e. Sig. value 
is 0.05 or smaller) justify the use of factor analysis (Pai and Huang, 2011). We have also checked the composite reliability to verify discriminant validity. The calculated composite reliability values were above the suggested minimum of 0.65 .

To analyse the relationship between the dependent variable (i.e. adoption of RFID) and the independent variable (i.e. usability of RFID), Pearson's product-moment correlation coefficients are used to measure the related index between variables (Pai and Huang, 2011). Table 2 represents the correlation between dependent (adoption) and independent (usability) variables. This table also includes the factor 'government support' and its correlation with the other two factors.

Table 2: Correlation among factors

\begin{tabular}{lrcc}
\hline & Usability & Adoption & Government support \\
\hline Usability & 1 & & \\
Adoption & .785 & 1 & \\
Government support & .928 & .717 & 1 \\
\hline
\end{tabular}

\section{Data analysis}

Regression analysis is used in this study to evaluate the relationship between the dependent and independent variable, and to test moderation effects.

Table 3: Results of the simple regression model

\begin{tabular}{lc}
\hline Variables & Standardised $\beta$ coefficients \\
\hline Control & \\
$\quad$ Business & $0.103^{*}$ \\
\hline Direct Effect & $0.782^{* * *}$ \\
$\quad$ Usability & 0.627 \\
\hline$R^{2}$ & 0.620 \\
$R^{2}$ adj & $83^{* * *}$ \\
$F$ & \\
\hline$* * * p<0.01 ; * * p<0.05 ; * p<0.10$ \\
\hline Dependent variable: Adoption \\
\hline
\end{tabular}

First we have tested the relationship between dependent variable (adoption of RFID) and independent variable (usability of RFID). As mentioned in Section 3.1, our responding companies belonged to many sub-sectors of logistics (logistics, freight forwarding, warehousing, etc.), and hence we have controlled for the effect of these sub-sectors using 'business' as a dummy control variable. For the regression discussed below, we first carried out the usual tests to check whether the assumptions of regression are valid for the data. We have tested for normality assumption of the error terms and checked for multi-collinearity and heteroskedasticity. We have verified and found that all assumptions for regression are satisfied. There was no evidence of multi-collinearity with all variable-inflation factors below the 
threshold of 10 (Hair et al., 2006). Table 3 shows the significant positive impact of usability (the independent variable) on adoption (the dependent variable). This proves our first hypothesis that the usability of RFID technology will have a positive impact on adoption of RFID.

To verify the moderating roles of size, barcode and government support, we employed moderated regression analysis. This involved running regressions in two stages ( $\mathrm{Li}$ and Atuahene-Gima, 2001; Hair, et al., 2006). In the first stage, the dependent variable (adoption) was regressed with usability, the control variable (business), and the three moderator variables (size, barcode and government support). In the second stage, we repeated the same regression but this time with the incorporation of interaction variables (i.e., usability $\times$ size, usability $\times$ barcode, and usability $\times$ government support) involving the three moderators. Size has been measured in four categories based on the number of employees $(<50, \cdot 50-249,250-499$ and $>500)$. Bar code is a Yes or No variable.

Like the case of the previous regression, we carried out the usual tests to verify the assumptions of regression. Though all other assumptions are satisfied, there was evidence of multi-collinearity with variable-inflation factors (VIF) for two of the three product-terms (usability $\times$ size and usability $\times$ barcode) above the threshold of 10 (Hair et al., 2006). To overcome this problem we employed an orthogonalizing procedure, which is based on replacing the interaction term with related residuals (Saville and Wood, 1991). To orthogonalise the interaction variable usability $\mathrm{x}$ size, we first ran a simple regression with this product-term (i.e., usability $\times$ size) as the dependent variable, and, usability and size as the independent variables. The unstandardized residual of this regression was used as a "true" measure of the interaction, replacing the product-term in the moderated regression. The other product term (usability $\times$ barcode) was also orthogonalised similarly. Inclusion of the orthogonalized product-terms reduced the VIF value to well within the acceptable limits, and did not affect the values of coefficients or their levels of significance.

The hypothesised moderating effects are validated by comparing the differences in the explanatory power (i.e., $R^{2}$ ) of the Stage 1 and Stage 2 regressions. If the difference between the R-squared values is statistically significant, the moderating effects are confirmed. The significance of the moderating effects of each of the three moderators is verified by looking at the significance of corresponding product-term. Results are shown in Table 4.

The results show that the difference in $R^{2}$ between Stage 1 regression and Stage 2 regression is highly significant at $1 \%$ level, demonstrating significant moderating effects. However, looking at the individual product terms, two (size and barcode) of the three moderators are not significant. Thus our results show that size of a company or the experience it has with barcode technology do not influence the usability and its link to the level of adoption of RFID. Thus our hypotheses $\mathrm{H} 2$ and $\mathrm{H} 3$ are not supported. Our results show that government support has strong moderating links, thereby strongly supporting H4.

Table 4: Results of the 2-stage moderated regression analysis 


\begin{tabular}{lll} 
& \multicolumn{1}{c}{ Stage 1 } & Stage 2 \\
\hline Control variable: Business & $0.132^{* *}$ & $0.106^{*}$ \\
Direct Effect: Usability & $0.792^{* * *}$ & $0.942^{* * *}$ \\
Size & $0.189^{* * *}$ & $0.150^{* *}$ \\
Barcode & -0.007 & -0.034 \\
Government support & -0.046 & -0.092 \\
\hline Moderating Effects & & \\
Usability $\times$ Size & & 0.176 \\
Usability $\times$ Barcode & & 0.0002 \\
Usability $\times$ Government support & & $0.194 * * *$ \\
\hline$R^{2}$ & 0.662 & 0.695 \\
$R^{2}$ adj & 0.645 & 0.669 \\
$\Delta R^{2}$ & & $0.033^{* *}$ \\
$F$ & $38 * * *$ & $27 * * *$ \\
\hline$* * * p<0.01 ; * * p<0.05 ; * p<0.10$ & & \\
\hline Dependent variable: Adoption & & \\
\hline
\end{tabular}

\section{Discussion and managerial implications}

Using the analysis of survey data, we have found support for two of the four hypotheses in the context of logistics sector in the UK. We have found that usability of RFID has significant impact on its adoption in the UK logistics sector. We have also found that this relationship is positively moderated by the level of government support but is not moderated by the size of the company or by the experience in using the barcode technology. These results have interesting managerial implications.

Our first finding on the strong relationship between usability (ease of use and usefulness) and adoption has been well documented in prior literature. In our study, we have used the construct of usability because our factor analysis produced a single factor (not two factors namely ease of use and usefulness), but many other studies have represented usability in terms of the two sub-factors. As we discussed in our literature survey, many studies that employed TAM (e.g., Pai and Uhang, 2011; Muller-Seitz et al., 2009) have confirmed the relationships between ease of use/usefulness and adoption of innovations.

However, the real contribution of our work lies in understanding the moderating influence of size, experience in using barcodes and government support. We have found that government support is a significant moderator. This is illustrated in Figure 2. This figure sketches the moderating effect of government support using the results of Table 4 . With a higher level of governmental support, the relationship between usability and adoption increases at a higher rate as usability increases. In contrast, with low or no governmental support, the relationship increases at a lower rate as usability increases. Thus, higher level of government support helps logistics firms to convert the usability of RFID into greater levels of adoption. 


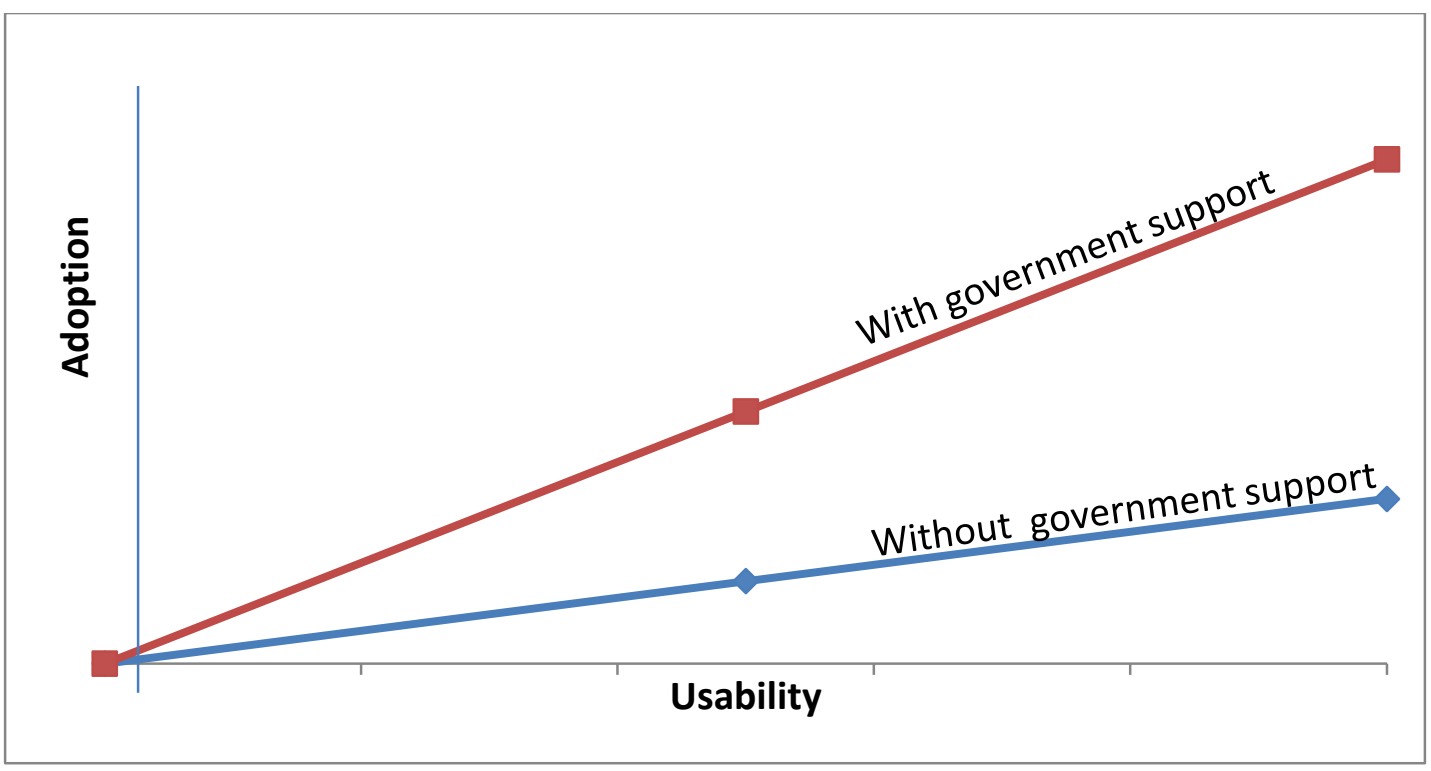

Figure 2: Graph showing the moderating effect of government support on the link between usability and adoption of RFID

As illustrated in Figure 2, there is a tendency for UK logistics firms to maximise benefits from usability of RFID when there is strong support from government (in the form of suitable regulations or training or funding). On the other hand, when there is insufficient help from the government, firms are not able to gain benefits from RFID even if they are positive about the usability of the technology. Though this is a new finding in the context of RFID and in the context of UK logistics, similar findings are available in the literature for other contexts (e.g., Mowery, 1983; Narin et al., 1997). Thus our study highlights the need for the government to help firms to fully utilise the potential of RFID. This result also highlights the important roles organisations such as the CILT and Universities can play in securing government support and passing the benefits to logistics firms. These organisations can secure funding from the government and organise training programmes regularly for the benefit of logistics firms. Government can also initiate further relevant research and development in RFID to help overcome any specific user-oriented issues (e.g., high cost).

We have found that size does not moderate the relationship between usability and adoption. Both small and large firms seem to enjoy the same level of benefit from RFID. This is an interesting finding of our paper. This finding will be encouraging news for small logistics firms as there does not seem to be any advantage enjoyed by large firms in harnessing the benefits of RFID. The absence of moderating role of size is contrary to some studies presented in the literature. For example, Swamidass and Kotha (1998) have found a weak moderating relationship of firm size on the relationship between advanced manufacturing technology use and performance in the context of 160 manufacturing firms in the US. It may be noted that the results of Swamidass and Kotha (1998) are more than ten years old and it is reasonable to believe that technology advancements have helped to reduce the initial costs of advanced technologies, reducing the impact of firm size. These technological developments are clearly evident in the case of RFID technologies, whose costs have drastically come down (Bunduchi et al., 2011; Smart et al., 2010). 
Perhaps the most surprising finding of our study is the absence of influence of experience in using barcodes on RFID usability-adoption link. This shows that the positive impact of usability of RFID on its adoption does not change whether the firm had previous experience with barcode technology or not. An experienced user of barcode may find many new uses of RFID, especially in the logistics sector. Such innovative uses of RFID in logistics include the ability to automatically detect and track items for more efficient inventory management, ability to track trucks using geographical positioning systems, ability to mix different items in a truck or in a warehouse since they can be easily separated with RFID information (Asif and Mandviwalls, 2005). Other innovative uses of RFID such as increased security control capabilities (Huber et al., 2007) are also important. Barcodes do not offer any security capability (Huber et al., 2007). In contrast, a user with limited experience with barcodes can consider adopting RFID for both conventional uses and for novel uses.

We believe that the absence of moderating role of barcode experience could indicate that the two technologies should be viewed as complementing rather than one replacing the other. RFID can be used only in applications where barcodes are not very useful. In applications where both technologies can be used, the choice of either technology may be made based on cost considerations and/or complementary uses. This view is consistent with similar observations in earlier studies (e.g., Nemeth et al., 2006) that the barcode system will not be replaced anytime soon as it is firmly implanted in all industries and hence both barcodes and RFID systems have to exist in parallel for a long time in future.

\section{Conclusions and future work}

In this era of technology innovation, many sophisticated and easy to use technologies are available to businesses. RFID is one such modern technology helping many businesses. Specifically, RFID is useful in the logistics sector in improving efficiencies of tracking, warehousing, loading and unloading, etc. Although initial investment of this technology is higher than that of other similar technologies (such as barcode), the range of coverage by RFID is much larger. Since RFID technology has been regarded an important technology that can provide strategic and operational advantages, it is necessary to understand what determines RFID adoption in the logistics industry. In this paper, we described such a study based on a survey questionnaire to understand the usability of the RFID to the UK logistics. With the help of CILT, we disseminated the survey questionnaire to companies in the UK logistics industry.

Our data analysis using regression analysis has shown that usability of RFID technology positively influences its adoption. This findings leads to another futuristic view of RFID that training on RFID will improve the knowledge of user and hence can encourage the logistics companies to adopt RFID. We have tried to verify the moderating effect of size of the company in the relationship between usability and adoption of RFID. Our result has not supported this hypothesis $(\mathrm{H} 2)$. We can claim that the size of the company (number of employees) is not a criterion to be considered for adoption of RFID. This is an important contribution of this paper. We have also found that previous experiences of a firm in using barcodes do not moderate the positive relationship between usability and adoption. We can interpret this result in such a way that awareness on RFID usability can help the businesses to 
adopt irrespective of their previous knowledge on specific technology. Our data analysis has supported the positive moderating effect of government support in the relationship between usability and adoption of RFID. Different forms of support from the Government, such as finance, new projects, training and simple regulations, can help the company in adopting the new technology, RFID in the UK logistics sector.

In this study, we have used the underlying theory 'technology acceptance model' to test the adoption of RFID in the UK logistics sector in general. We have not considered the influence of service types of logistics companies on the adoption of RFID technology. Future study can include the types of services and study the effects of technological, organizational, and environmental factors on the adoption of RFID technology in UK logistics industry (Lin and Ho, 2009a). We have carried out the survey with limited number of small-sized or mediumsized companies and this can be extended to large companies. We focussed on the UK for our study but similar studies can be conducted for other geographical regions in the future. 


\section{References}

Anderson R.E., and Srinivasan. S.S. (2003). E-satisfaction and e-loyalty: A contingency framework. Psychology and Marketing, 20 (2), 123-138.

Asif, Z., M. Mandviwalla. 2005. Integrating the supply chain with RFID: A technical and business analysis. Communications of the Association for Information Systems, 15 393-427.

Attaran, M. (2007). RFID: an enabler of supply chain operations. Supply Chain Management: An International Journal, 12 (4), 249-257.

Bhattacharya, M., Chu, C. H., and Mullen, T. (2008). A Comparative Analysis of RFID Adoption in Retail and Manufacturing Sectors. IEEE International Conference on RFID, 241-249.

Bowersox, D. J., and Closs, D. J. (1996). Logistics Management: The Integrated Supply Chain Process. New York: McGraw-Hill.

Bunduchi, R.. C. Weisshaar, A. U. Smart (2011), Mapping the benefits and costs associated with process innovation: The case of RFID adoption. Technovation, 31(9), 505-521.

Cardiel, I. A., Gil, R. H., Somolinos, C. C., and Somolinos, J. C. (2012), A SCADA oriented middleware for RFID technology. Expert Systems with Applications, 39(12), 11115-11124.

Chen, J. C., C-H Cheng, P.Tsang, B. Huang (2012), Supply chain management with lean production and RFID application: A case study. Expert Systems with Applications, In Press.

Chong, A. Y-L. and Chan, F. T.S. ( 2012), Structural equation modeling for multi-stage analysis on Radio Frequency Identification (RFID) diffusion in the health care industry. Expert Systems with Applications, 39(10), 8645-8654.

Curtin, J., Kauffman, R., and Riggins, F. (2007). Making the 'most' out of RFID technology: A research agenda for the study of the adoption, usage and impact of RFID. Information Technology and Management, 8 (2), 87-110.

Davis, F. D., Bagozzi, R. P., and Warshaw, P. R. (1989). User acceptance of computer technology: A comparison of two theoretical models. Management Science, 35, 982-1003.

Fornell, C., Larcker, D., 1981. Structural equation models with unobservable variables and measurement error. Journal of Marketing Research 18 (1), 39-50.

Hair, J.F., Black, W.C., Babin, B.J., Anderson, R.E., Tatham, R.L., 2006. Multivariate data analysis. $6^{\text {th }}$ edition Prentice-Hall, New Jersey.

Hardgrave, B., Aloysius, J., Goyal, S., and Spencer, J. (2008a). Does RFID improve inventory accuracy? A preliminary analysis. Fayetteville, AR: Information Technology Research Institute, Sam M. Walton College of Business, University of Arkansas.

Hardgrave, B., Langford, S., Waller, M., and Miller, R. (2008b). Measuring the impact of RFID on out of stocks at Wal-Mart. MIS Quarterly Executive, 7 (4), 181-92.

Holmqvist, M., and Stefansson, G. (2006a). 'SMART GOODS' and mobile RFID: A case with innovation from Volvo. Journal of Business Logistics, 27 (2), 251-72.

Holmqvist, M., and Stefansson, G. (2006b). Mobile RFID: A Case from Volvo on Innovation in SCM. Hawaii: Proceedings of the 39th Hawaii International Conference on System Sciences.

Hossain, M. M., and Prybutok, V. R. (2008). Consumer Acceptance of RFID Technology: An Exploratory Study. IEEE Transactions on Engineering Management, 55 (2), 316 - 328 .

Huber, N. K. Michael, and L. McCathie (2007). Barriers to RFID adoption in the supply chain. In RFID Eurasia, 1st Annual, 1-6, 2007. 
Karkkainen, M. (2003). Increasing efficiency in the supply chain for short shelf life goods using RFID tagging. International Journal of Retail and Distribution Management, 31 (10), 529-36.

Lee, C.K.H., K.L. Choy, G.T.S. Ho, K.M.Y. Law (2013),A RFID-based Resource Allocation System for garment manufacturing. Expert Systems with Applications, 40(2), 784-799.

Lee, L. S., Fiedler, K. D., and Smith, J. S. (2008). Radio frequency identification (RFID) implementation in the service sector: A customer-facing diffusion model. International Journal of Production Economics, 112, 587-600.

Li, H. and Atuahene-Gima, K. 2001. Product innovation strategy and the performance of new technology ventures in China. Academy of Management Journal, 44:1123-1134.

Li, S., Godon, D., and Visich, J. K. (2010). An exploratory study of RFID implementation in the supply chain. Management Research Review, 33 (10), 1005-1015.

Lin, C. Y., and Ho, Y. H. (2009a). An Empirical Study on the Adoption of RFID Technology for Logistics Service Providers in China. International Business Research, 2 (1), 23-36.

Lin, C. Y., and Ho, Y. H. (2009b). RFID technology adoption and supply chain performance: an empirical study in China's logistics industry. Supply Chain Management: An International Journal, 369-378.

Lin, J.T., Hou, J-L., Chen, W-C. and Huang, C-H. (2005). An RFID application model for the publication industry: a Taiwan perspective, International Journal of Electronic Business Management, 3 (2), 129-139.

Luyskens, C., and Loebbecke, C. (2007). RFID Adoption: Theoretical Concepts and Their Practical Application in Fashion. In T. McMaster, D. Wastell, E. Ferneley, and J. DeGross, Organizational Dynamics of Technology-based Innovation: Diversifying the Research Agenda (Vol. 235, pp. 345-361). Boston: Springer.

McFarlane, D., and Sheffi, Y. (2003). The impact of automatic identification on supply chain operations. The International Journal of Logistics Management, 14 (1), 1-17.

Moon, K. L., and Ngai, E. W. (2008). The adoption of RFID in fashion retailing: a business valueadded framework. Industrial Management and Data Systems , 108 (5), 596-612.

Mowery C. D. (1983), Economic theory and government technology policy. Policy Sciences, 16 (1), 27-43.

Muller-Seitz, G., Dautzenberg, K., Creusen, U., and Stromereder, C. (2009). Customer acceptance of RFID technology: Evidence from the German electronic retail sector. Journal of Retailing and Consumer Services. 16, 31-39.

Narin, F.. Hamilton, K. S. and Olivastro, D. (1997). The increasing linkage between U.S. technology and public science. Research Policy, 26 (3), 317-330.

Nemeth, P., Toth, L., and Hartvanyi, T. (2006). Adopting RFID in supply chains., 2006 IEEE International Conference on Mechatronics, 263 - 266.

Ngai, E., Cheng, T., Lai, K. H., Chai, P., Choi, Y., and Sin, R. (2007). Development of an RFIDbased traceability system: experiences and lessons learned from an aircraft engineering company. Production and Operations Management, 16 (5), 554-68.

Nunnally, J.L., 1978. Psychometric Theory $2^{\text {nd }}$ edition. MaGraw-Hill, New York.

Ozelkan, E., and Galambose, A. (2008). When does RFID make business sense for managing supply chains? International Journal of Information Systems and Supply Chain Management, 1 (1), 15-47. 
Pai, F. Y., and Huang, K. I. (2011). Applying the Technology Acceptance Model to the introduction of healthcare information systems. Technological Forecasting and Social Change, $78,650-660$.

Poon, T.C, K.L. Choy, H. K.H. Chow, H. C.W. Lau, F. T.S. Chan, Ho, K.C. (2009). A RFID casebased logistics resource management system for managing order-picking operations in warehouses. Expert Systems with Applications, 36(4), 8277-8301.

Riedel, J., Pawar, K. S., Torroni, S., and Ferrari, E. (2008). A Survey of RFID Awareness and Use in the UK Logistics Industry. In: Kreowski, H-J., Scholz-Reiter, B. and Haasis, H-D. (Eds.), Dynamics in Logistics, Springer Berlin Heidelberg, pp: 105-115.

Rong, S. (2004). Radio Frequency Identification (RFID) and Its Application in the Library. Hangzhou: The Library of Hangzhou Teacher's College.

Saville, D.J., and Wood, G.R., (1991). Statistical Methods: The Geometric Approach. Springer.

Schmitt, P., Thiesse, F., and Fleisch, E. (2007). Adoption and Diffusion of RFID Technology in the Automotive Industry. Switzerland: 15th European Conference on Information Systems.

Smart, A.U., Bunduchi, R., Gerst, M. (2010). The costs of interorganizational IT innovation adoption: RFID technologies in supply networks. International Journal of Operations and Production Management, 30(4), 423-447.

Spekman, R., and Sweeney, P. (2006). RFID: from concept to implementation. International Journal of Physical Distribution and Logistics Management, 36 (10), 736-754.

Sundaram, D., Zhou. W., Piramuthu, S., and Pienaar, S. (2010). Knowledge-based RFID enabled Web Service architecture for supply chain management. Expert Systems with Applications, 37 (12) , 7937-7946.

Swamidass, P. M. and Kotha, S. (1998). Explaining manufacturing technology use, firm size and performance using a multidimensional view of technology. Journal of Operations Management, 17 (1), 23-37.

Sweeney, P. J. (2005). RFID for dummies. Wiley Publishing, Indianapolis, IN .

Tan, T-H., and Chang, C-S. (2010), Development and evaluation of an RFID-based e-restaurant system for customer-centric service. Expert Systems with Applications, 37(9), 6482-6492.

Twist, D. C. (2005). The impact of radio frequency identification on supply chain facilities. Journal of Facilities Management, 3 (3), 226-239.

Ustundag, A., and Tanyas, M. (2009). The impacts of radio frequency identification (RFID) technology on supply chain costs. Transportation Research Part E, 45 (1), 29-38.

Venkatesh, V., and Davis, F. D. (2000). A theoretical extension of the technology acceptance model: Four longitudinal field studies, Management Science, 46 (2), 186-204.

Wang, Y. M., Wang, Y. S., and Yang, Y. F. (2010). Understanding the determinants of RFID adoption in the manufacturing industry. Technological Forecasting and Social Change, 77, 803815.

White, G. R., Gardiner, G., Prabhakar, G., and Razak, A. A. (2007). A Comparison of Barcoding and RFID Technologies in Practice. Journal of Information, Information Technology, and Organizations, 2, 119-132.

Wyld, D. C. (2006). RFID 101: the next big thing for management. Management Research News, 29 (4), 154-173. 
Yi, M.Y., and Hwang, Y. (2003). Predicting the use of web-based information systems: selfefficacy, enjoyment, learning goal orientation, and the technology acceptance model. International Journal of Human-Computer Studies, 59, 431-449.

Zona, F., Zattoni, A., and Minichilli, A. (2012). A Contingency Model of Boards of Directors and Firm Innovation: The Moderating Role of Firm Size. British Journal of Management, DOI: $10.1111 / \mathrm{j} .1467-8551.2011 .00805 . \mathrm{x}$ 